\title{
Clinico-pathology, diagnosis and management of Cysticercus fasciolaris and Hymenolepis diminuta co-infection in wistar rats
}

\author{
Y. Damodar Singh and Rahul Singh Arya
}

Department of Veterinary Pathology, College of Veterinary Sciences \& Animal Husbandry, Central Agricultural University, Selesih, Aizawl - 796014, Mizoram, India.

Corresponding author: Rahul Singh Arya, e-mail: aryarahulsingh@gmail.com, YDS: dsyengkhom66@gmail.com Received: 12-10-2014, Revised: 18-12-2014, Accepted: 26-12-2014, Published online: 29-01-2015

doi: 10.14202/vetworld.2015.116-120. How to cite this article: Singh YD, Arya RS (2015) Clinico-pathology, diagnosis and management of Cysticercus fasciolaris and Hymenolepis diminuta co-infection in wistar rats, Veterinary World, 8(1): 116-120.

\begin{abstract}
Aim: The present study was undertaken to study the pathology and control of sudden unexplained mortality in wistar rats.

Materials and Methods: This study was conducted in a colony of 25 male wistar rats where there was mortality of nine rats. The dead rats were subjected to thorough post-mortem examination and necropsy samples were processed for hematoxylin and eosin staining for histopathological studies. Faecal samples of live rats were studied for the presence of parasitic eggs. Treatment with anthelmintics was given to manage the mortality and infections.

Results: The investigation revealed a natural co-infection of Cysticercus fasciolaris and Hymenolepis diminuta in wistar rats, which were pathogenic enough to cause mortality. Typical lesions associated with the parasites were found in the dead rats. The mortality and infection were managed with common anthelmintics.
\end{abstract}

Conclusion: $C$. fasciolaris and $H$. diminuta infection can cause mortality in wistar rats even when individually they cause asymptomatic infection. The mortality and infection can be managed with common anthelmintics.

Keywords: anthelmintics, co-infection, Hymenolepis diminuta, Mizoram, Taenia taeniaeformis, wistar rats

\section{Introduction}

Taenia taeniaeformis occurs all over the world in small intestines of their definitive host, cats and related carnivores. The infected definitive host voids thousands of eggs daily which then infect the intermediate host through contamination of feed and water. These include rodents and less frequently lagomorphs. Its metacestode, a strobilocercus (Cysticercus fasciolaris) develops in the liver of the infected rodents. The life cycle is completed when the cats consume infected rodents (laboratory and wild) or any other intermediate host [1-8]. The parasite is of zoonotic significance and human beings can act as accidental intermediate host $[9,10]$. Hymenolepis diminuta, the "rat tapeworm" is also a zoonotic parasite [11-14].

Its occurrence has been considered rare in laboratory rodents. Its epidemiology involves primarily wild rodents and even primates. Intermediate hosts include beetles (Tribolium confusum, Tenebrio molitor), moths or fleas (Nosopsyllus fasciatus) [2,3,6,8,15]. The infection with both parasites in rodents is considered generally asymptomatic, with rare complications [1-3,5,1619]. It is recommended to practice depopulation of the infected colonies for the control of both parasites [3]. Both parasites had been reported from Mizoram [20-21].

Here, we report the investigation of mortality in wistar rats associated with co-infection of

Copyright: The authors. This article is an open access article licensed under the terms of the Creative Commons Attributin License (http:// creative commons.org/licenses/by/2.0) which permits unrestricted use, distribution and reproduction in any medium, provided the work is properly cited.
C. fasciolaris and $H$. diminuta and its management with common anthelmintics.

\section{Materials and Methods}

\section{Ethical approval}

There was no sacrifice or animal experimentation involved in the present study therefore approval from Institutional Animal Ethics Committee was not required. However, there was no deviation from rules of ethical treatment to animals during the study.

\section{Animals}

Mortality was observed in 9 out of 25 male rats of age between 3 and 5 months kept in the laboratory animal house of Department of Pharmacology and Toxicology College of Veterinary Sciences \& A.H., Central Agricultural University, Selesih, Aizawl for research purpose. Post-mortem was conducted on all the 9 rats found dead in their cages during a period of 7 days.

\section{Clinical examination}

The live rats of affected colonies were observed for external signs of disease for a month from the commencement of mortality, considered as day-1 (Table-1). Fecal samples from the affected colonies were examined every $3^{\text {rd }}$ day by preparing direct fecal smear from the day-1.

\section{Post-mortem examination and sample collection}

A thorough and scientific necropsy was conducted of the dead rats and all important findings were photographed. The livers showing parasitic cysts were removed and collected in normal saline solution 
warmed up to $37^{\circ} \mathrm{C}$. Morphology of the larvae was studied for their identification after dissecting the capsules from the freshly collected samples [2]. The gastrointestinal tracts were examined and the tapeworms as well as the intestinal contents were collected for detecting the presence of parasitic ova by preparing direct fecal smears. For histopathological studies representative tissue samples with parasitic cyst in-situ were preserved in $10 \%$ neutral buffered formalin.

\section{Histopathological Studies}

Tissue samples were embedded in paraffin wax and $4-5 \mu \mathrm{m}$ thick sections were cut for routine hematoxylin and eosin staining [22]. Observations were recorded by photomicrography.

\section{Results and discussion}

\section{Clinical and post-mortem findings}

The affected rats were grossly weak, dull, with rough hair coat and pale mucus membranes. Liver of 7 out of 9 dead rats revealed white cysts about 7-10 mm in diameter embedded in their parenchyma (Table-1, Figures-1 and 2). The cysts had a well-defined capsule wall. The number of cysts observed varied from 1 to as many as 11 in a liver (Figure-2).Variable number of parasitic cysts indicate that the infestation was gradually increasing due to continuous exposure to eggs of T. taeniaeformis. On dissecting the cysts, white colored and segmented strobilocercii were found coiled inside (Figure-1). They were around $60-80 \mathrm{~mm}$ in length and the scolices were large with two rows of rosettlar hooks. The segmented strobila lacked genital organs. The morphology of the strobilocercii and their anatomical site of predilection in rats confirmed them to be $C$. fasciolaris [2-3].

Adult tapeworms were also found in the intestines of all 9 dead rats (Table-1). There was thinning of the intestinal wall, and the tapeworm could be located from the serosal surface of the intestines (Figure-3). They were around $50 \mathrm{~mm}$ long and 3-4 $\mathrm{mm}$ wide. The scolices were pear shaped, unarmed and bore suckers. At the most only 2 or 3 scolices could be recovered from a rat. The eggs were spherical, embryonated with three pairs of small hooks (Figure-4). The morphological characters of worms and eggs

Table-1: Mortality pattern, diagnosis and treatment during the course of mortality

\begin{tabular}{ccccc}
\hline $\begin{array}{c}\text { Day } \\
\text { of Rats } \\
\text { dead }\end{array}$ & given & $\begin{array}{c}\text { Number } \\
\text { of Rats } \\
\text { infected with infected with } \\
\text { C. fasciolaris }\end{array}$ & $\begin{array}{c}\text { Number } \\
\text { of Rats }\end{array}$ \\
\hline 1 & 1 & Not given & 1 & 1 \\
2 & 2 & Not given & 1 & 2 \\
3 & 3 & Fentas Plus ${ }^{\circledR}$ & 2 & 3 \\
4 & 1 & Fentas Plus ${ }^{\circledR}$ & 1 & 1 \\
5 & 1 & Not given & 1 & 1 \\
6 & 0 & Not given & 0 & 0 \\
7 & 1 & Not given & 1 & 1 \\
\hline
\end{tabular}

C. fasciolaris $=$ Cysticercus fasciolaris,

$H$. diminuta $=$ Hymenolepis diminuta and its site of predilection confirmed the species as H. diminuta [2-3]. The affected rats revealed severe hemorrhagic enteritis with catarrhal and blood tinged intestinal contents in almost all portions of intestines (Figure-3). Apart from mild to moderate the grossly visible congestion, other visceral organs revealed no

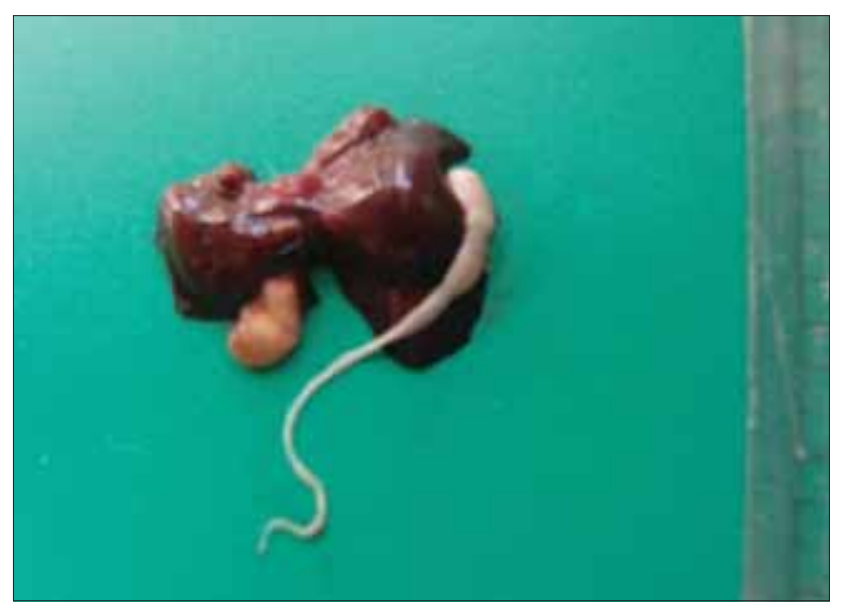

Figure-1: Liver of Wistar rat with a Cysticercus fasciolaris dissected out of a cyst.

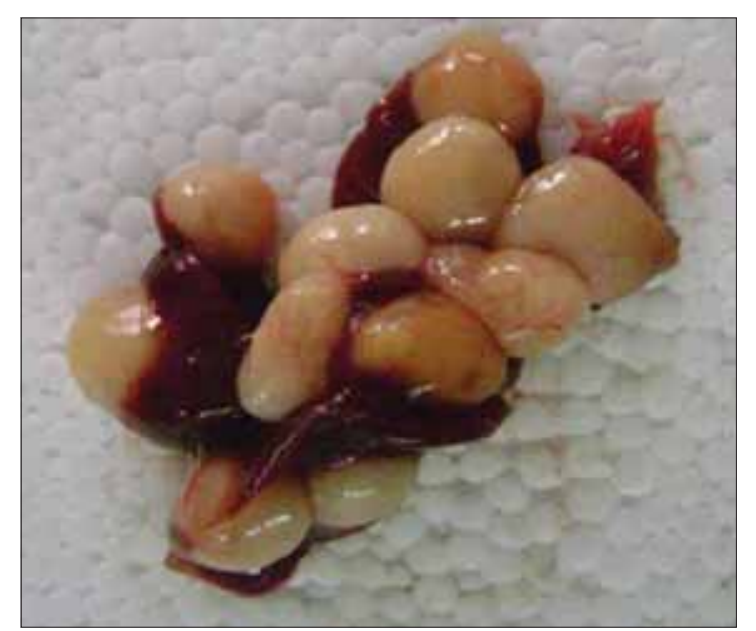

Figure-2: Liver of Wistar rat with 11 cysts of Cysticercus fasciolaris.

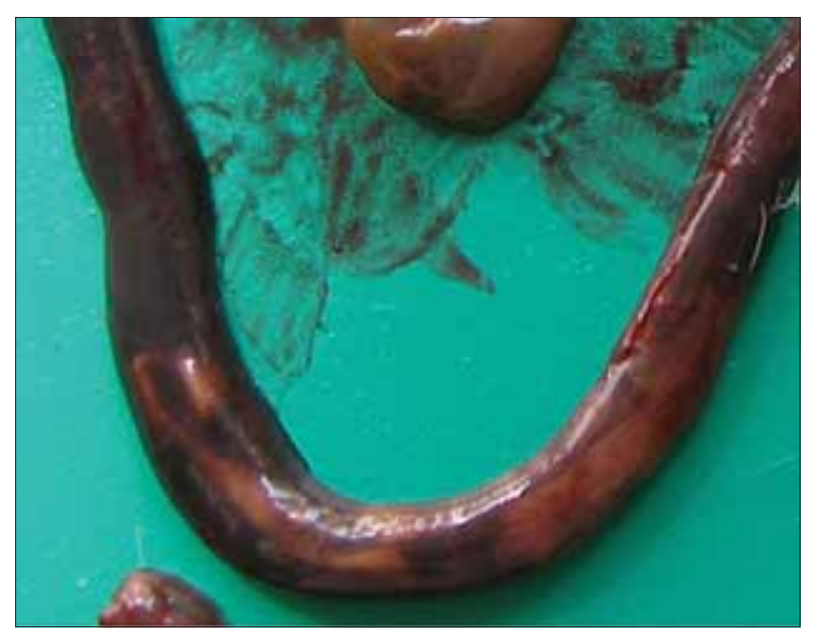

Figure-3: Adult tapeworm (Hymenolepis diminuta) visible through the serosa of intestine of rat. 


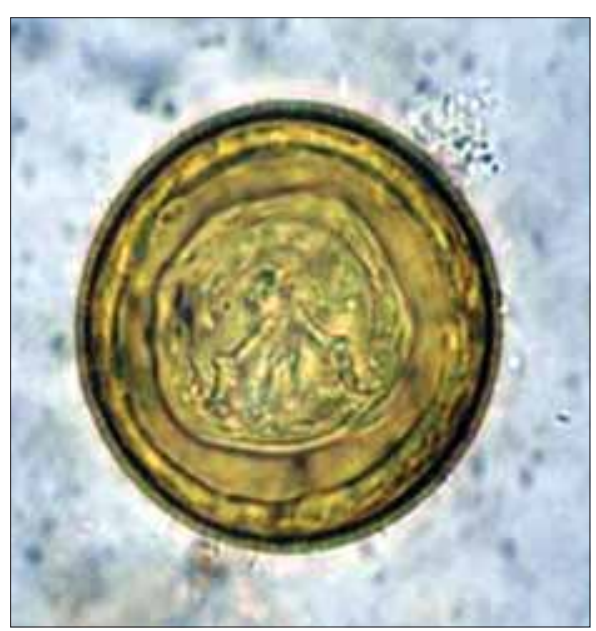

Figure-4: Egg of Hymenolepis diminuta $(\times 1000)$

specific pathological changes. Random sampling of fecal pellets from the rat colonies also revealed the eggs of $H$. diminuta on fecal smear examination. Mild infections with $H$. diminuta have been considered non-pathogenic [23]. However, it had been reported that anemia and disturbance in liver function can occur in $H$. diminuta infection in rats [19]. The immune system of the rat can control the number of $H$. diminuta in its intestines [16], which may be a reason of finding only few parasites in the studied rats. Emaciation and catarrhal hemorrhagic enteritis were a consistent finding in the dead rats. A heavy infection with this parasite can cause increased intestinal permeability with other pathological changes varying from catarrhal enteritis to chronic enterocolitis. Thus the normal physiology of the infected host is disturbed [3].

\section{Histopathology}

Histopathology of affected portion of the liver revealed cross section of parasite surrounded by a developing capsule of fibrous connective tissue, a zone of infiltrating inflammatory cells. The fibrous connective tissue comprised of loose collagen fibers and some fibroblasts. The inflammatory zone comprised of extensive infiltration of neutrophils, Kupffer cells and a few epitheloid cells in some foci (Figures-5 and 6). The blood capillaries in the hepatic parenchyma proximal to the capsule revealed extensive engorgement (Figure-6). Similar findings have been reported by other researchers $[5,24]$. The hepatocytes around the affected area were unremarkable and apparently normal. It is, therefore, possible that if infection is low the affected host may seem clinically normal as generally accepted [1-3]. However, there are few reports of association of parasitic cysts with development of neoplasms $[5,17,18,25]$.

\section{Treatment and Control}

The remaining rats (16 out of 25) were treated with Fentas Plus ${ }^{\circledR}$ (Fenbendazole-150 mg + Praziquantel-50 mg) diluted in $25 \mathrm{ml}$ of distilled water and given at the rate of 30 and $10 \mathrm{mg} / \mathrm{kg}$ body weight according to standard recommended therapy [26].

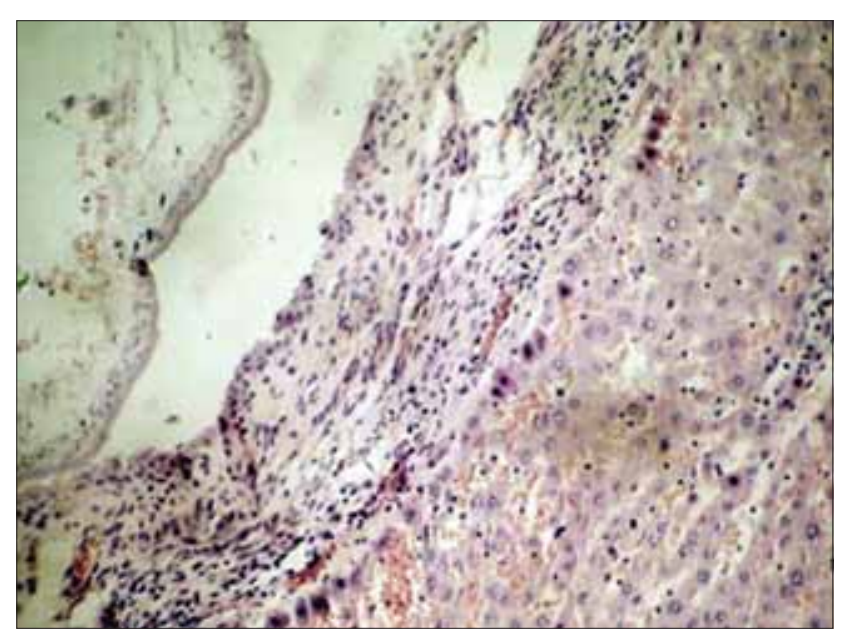

Figure-5: Proliferation of fibrous connective tissue with infiltration of mononuclear cells in adjoining parenchyma of liver to Cysticercus fasciolaris cysts ( $\mathrm{H}$ and $\mathrm{E}, \times 400$ ).

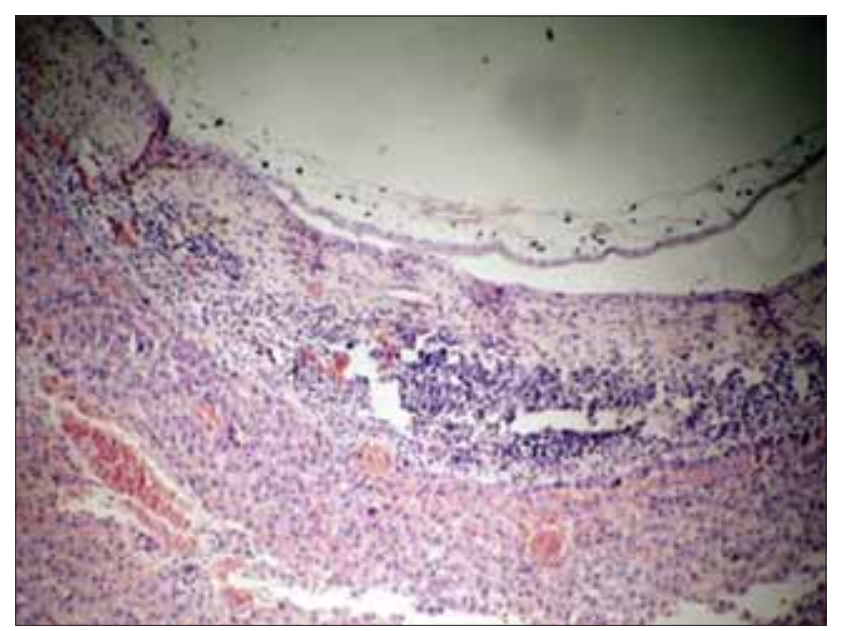

Figure-6: Severe vascular engorgement and proliferation of fibrous connective tissue with infiltration of mononuclear cells in adjoining parenchyma of liver to Cysticercus fasciolaris cysts $(\mathrm{H}$ and $\mathrm{E}, \times 400)$.

Treatment was given on day 3 and 4 (Table-1) since the commencement of mortality. The stored litter and feed were discarded and replaced with a new lot. Only two rats which were already showing severe illness died post-treatment (Table-1). Two weeks after the treatment a rat, which died due to accidental trauma, revealed a small capsulated cyst in the liver on post-mortem examination (Figure-7). It was smaller in size, about 3-4 $\mathrm{mm}$ in diameter, as compared to previously observed ones and did not contain the strobilocercus. The intestines were also free of tapeworms. The periodic examination of fecal smears also did not reveal any tapeworm eggs after the treatment with anthelmintics. Individually both parasites are not known to cause acute mortality at the observed level. The co-infection with both helminths seems to have resulted in the observed disease condition and mortality in affected rats. Involvement of secondary bacterial infection also seems likely. However, as there was no antibiotic treatment given and the mortality stopped after anthelmintic administration and hence, 


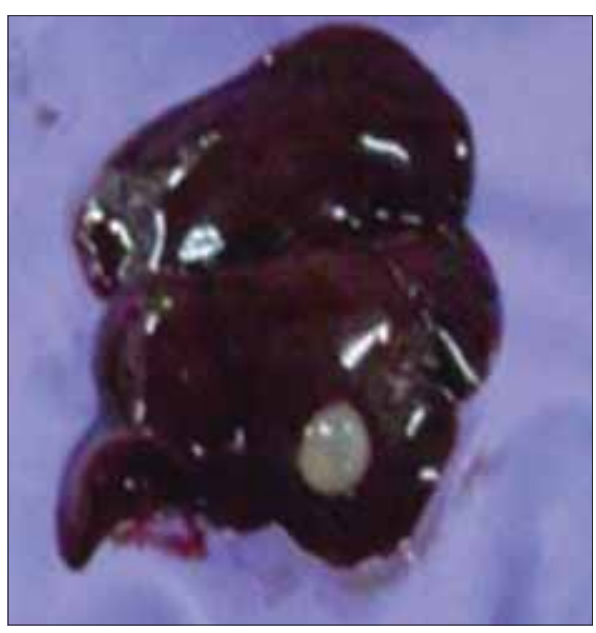

Figure-7: A reduced cyst found in the liver of a rat which died after treatment with anthelmintics.

it seems most probable that the bacteria involved were probably opportunistic pathogens.

\section{Conclusion}

To our knowledge this is the first report of mortality at remarkable level associated with co-infection of $C$. fasciolaris and $H$. diminuta and its treatment and control with common anthelmintics, from north eastern hilly region of India. According to the findings of present study it is concluded that co-infection of $C$. fasciolaris and $H$. diminuta can cause mortality in wistar rats. It was also concluded that the mortality and the infection can be controlled with common anthelmintics. The study opens scope for avoiding depopulation and replacement of rodent colonies especially in North Eastern Hilly region of India where such a practice can be expensive and time consuming. Considering the epidemiological aspect, it can be indirectly concluded that life cycle stage of T. taeniaeformis exist in local cats and possibly other wild felids and rodents. The rodents in the region also harbor $H$. diminuta. There is definite evidence of contamination of laboratory animal house with cat feces and infected insect intermediate hosts of $H$. diminuta. Since both the parasites have zoonotic significance, their potential public health hazard in the region is emphasized by the present study. The study highlights the need for control measures required for breaking the life cycle of the parasites, strict hygiene and biosecurity measures in the laboratory houses.

\section{Authors' contributions}

YDS conducted the study and data recording. RSA analyzed the data. Manuscript was drafted and revised by RSA under the guidance of YDS. Both authors read and approved the final manuscript.

\section{Acknowledgements}

The authors are thankful to the Dean, Head of Department of Pathology and Head of Department of Pharmacology and Toxicology, College of Veterinary
Science, Central Agricultural University, Selesih, India for providing fund and facilities to carry out the present study.

\section{Competing Interests}

The authors declare that they have no competing interests.

\section{References}

1. Jithendran, K.P. and Somvanshi, R. (1998) Experimental infection of mice with Taenia taeniaeformis eggs from cats - Course of infection and pathological studies. Indian J. Exp. Biol., 36(5): 523-535.

2. Soulsby, E.J.L. (2005) Cestodes. In: Helminths, arthropods and protozoa of domesticated animals, 7th ed, Bailliere Tindall, Elsevier, India.

3. Baker, D.G. (2007) Parasites of rats and mice. In: Flynn's parasites of laboratory animals, 2nd ed, Blackwell publishing, Ames.

4. Singla, L.D., Aulakh, G.S., Sharma, R., Juyal, P.D. and Singh, J. (2009) Concurrent infection of Taenia taeniaeformis and Isospora felis in a stray kitten: a case report. Vet. Med., 54(2): 81-83.

5. Karim, A.J. (2010) Scanning electron microscopy and histological morphology of Cysticercus fasciolaris which induced fibrosarcomas in laboratory rats. Ann. Microsc., 10: 44-48.

6. Kataranovski, M., Zolotarevski, L., Belij, S., Mirkov, I., Stošić, J., Popov, A. and Kataranovski, D. (2010) First record of Calodium hepaticum and Taenia taeniaeformis liver infection in wild Norway rats (Rattus norvegicus) in Serbia. Arch. Biol. Sci., 62(2): 431-440.

7. Rodríguez-Vivas, R.I., Panti-May, J.A., Parada-López, J., Hernández-Betancourt, S.F. and Ruiz-Piña, H.A. (2011) The occurrence of the larval cestode Cysticercus fasciolaris in rodent populations from the Cuxtal ecological reserve, Yucatan, Mexico. J Helminthol., 85(4): 458-461.

8. Pakdel, N., Naem, S., Rezaei, F. and Chalehchaleh, A.A. (2013) A survey on helminthic infection in mice (Mus musculus) and rats (Rattus norvegicus and Rattus rattus) in Kermanshah, Iran. Vet. Res. Forum., 4(2): 105-109.

9. Miyazaki, I. (1991). Helminthic Zoonoses. International Medical Foundation of Japan, Tokyo, p494.

10. Ekanayake, S., Warnasuriya, N.D., Samarakoon, P.S., Abewickrama, H., Kuruppuarachchi, N.D. and Dissanaike, A.S. (1999) An unusual 'infection' of a child in Sri Lanka with Taenia taeniaeformis of the cat. Ann Trop. Med. Parasitol., 93(8): 869-873.

11. Mowlavi, G., Mobedi, I., Mamishi, S., Rezaeian, M., HaghiAshtiani, M.T. and Kashi, M. (2008) Hymenolepis diminuta (Rodolphi, 1819) infection in a child from Iran. Iran. J. Publ. Health, 37(2): 120-122.

12. Karuna, T. and Khadanga, S. (2013) A case of Hymenolepis diminuta in a young male from Odisha. Trop Parasitol., 3(2): $145-147$.

13. Kołodziej, P., Rzymowska, J., Stępień-Rukasz, H., Lorencowicz, R., Lucińska, M. and Dzióbek, M. (2014) Analysis of a child infected with Hymenolepis diminuta in Poland. Ann. Agri. Environ. Med., 21(3): 510-511.

14. Tiwari, S., Karuna, T. and Rautaraya, B. (2014) Hymenolepis diminuta infection in a child from a rural area: A rare case report. J. Lab. Physician., 6(1): 58-59.

15. Makki, M.S., Shahbazi, F., Teimoori, S., Rokni, M.B., Abaei, M.R., Mobedi, I., Hassanpour, G. and Mowlavi, G. (2011) Establishment of Hymenolepis diminuta life cycle to provide parasite mass production. Iran. J. Parasitol., 6(2): 60-63.

16. Andreassen, J. and Hopkins, C.A. (1980) Immunologically mediated rejection of Hymenolepis diminuta by its normal host, the rat. J. Parasitol., 66(60: 898-903. 
17. Kohn, D.F. and Barthold, S.W. (1984) Biology and diseases of rats. In: Fox, J.G., Cohn, B.J. and Loew, F.M., editors. Laboratory animal medicine. Academic Press, Orlando, Florida, p91-122.

18. Hanes, M.A. (1995) Fibrosarcomas in two rats arising from hepatic cysts of Cysticercus fasciolaris. Vet. Pathol., 32(4): 441-444.

19. Goswami, R., Singh, S.M., Kataria, M. and Somvanshi, R. (2011) Clinicopathological studies on spontaneous Hymenolepis diminuta infection in wild and laboratory rats. Braz. J. Vet. Pathol., 4(2): 103-111.

20. Malsawmtluangi, C. and Tandon, V. (2009) Helminth parasite spectrum in rodent hosts from bamboo growing areas of Mizoram, North-east India. J. Parasit. Dis., 33(1\&2): 28-35.

21. Malsawmtluangi, C., Prasad, P.K., Biswal, D.K. and Tandon, V. (2011) Morphological and molecular identification of the metacestode parasitizing the liver of rodent hosts in bamboo growing areas of Mizoram, northeast India. Bioinformation, 7(8): 393-399.

22. Luna, L.G. (1968) Manual of Histologic Staining Methods of the AFIP, $3^{\text {rd }}$ ed., McGraw-Hill, New York.

23. Insler, G.D. and Roberts, L.S. (1976) Hymenolepis diminuta: lack of pathogenecity in the healthy rat host. Exp. Parasitol., 39(3): 351-357.

24. Moudgil, A.D., Singla, L.D., Gupta, K., Daundkar, P.S. and Vemu, B. (2014) Histopathological and morphological studies on natural Cysticercus fasciolaris infection in liver of Wistar rats. J. Parasit Dis., doi: 10.1007/s12639-014-0488-5.

25. Irizarry-Rovira, A.R., Wolf, A. and Bolek, M. (2007) Taenia taeniaeformis induced metastatic hepatic sarcoma in a pet rat (Rattus norvegicus). J. Exotic Pet Med., 16(1): 45-48.

26. McKellar, Q.A. (1989) Drug dosages for small mammals. In Pract, 11: 57-61.

$* * * * * * * *$ 